\title{
Do Territorial Control and the Loss of Territory Determine the Use of Indiscriminate Violence by Incumbent Actors? An Examination of the Syrian Civil War in Aleppo over 45 weeks
}

\section{by Evan Tyner}

\section{(cc) $\mathrm{BY}$}

This work is licensed under a Creative Commons Attribution 3.0 License.

\begin{abstract}
This study tests the 'control-collaboration' model detailed by Stathis Kalyvas in The Logic of Violence in Civil War (2006). The control-collaboration model makes various theoretical claims on the relationship between territorial control and the use and motivations of violence (whether selective or indiscriminate). This study tests two of the key claims made in the model: 1 . There is an inverse relationship between level of territorial control and the use of indiscriminate violence; and, 2. The loss of territory encourages the use of indiscriminate violence. Using data on civilian and child deaths taken from the 'Syrian Martyr Database', this study examines the relationship between territorial control and territorial loss, and the use of indiscriminate violence by incumbent (Syrian state) forces. Examining the levels of territorial control/loss and the extent of civilian and child casualties in Aleppo, Syria, results of the study largely support the theoretical assumptions outlined by Kalyvas.
\end{abstract}

Keywords: indiscriminate violence, selective violence, territorial control, territorial loss, civilian casualties, incumbent actors, insurgents

\section{Introduction}

The Syrian Conflict (or Civil War) has raged since July 2011, resulting in a death toll of over 250,000 the displacement of 12 million people (United Nations, 2015). Since the onset of the conflict the balance of power between warring factions has varied greatly, with armed opposition groups, proxy forces (such as Hezbollah) and foreign actors (such as Russia and Iran) influencing the progression and security dynamics of the civil war and developing competing spheres of influence. The complex nature of the Syrian Civil War makes it a very interesting, yet to date scarcely researched, topic for micro-dynamic study. The controlcollaboration model can prove a useful tool in helping to understand and potentially improve the security and humanitarian crisis, which through defining the use of indiscriminate violence can draw attention to the causes, nature and location of some of the most brutal areas of conflict in the world.

Political theorist Hannah Arendt concluded that all violence is instrumental and occurs where power is in jeopardy (Arendt, 1969). Political scientist and civil-war expert Stathis Kalyvas has built on this notion in the formation of his 'control-collaboration' model. The premise of the control-collaboration model stipulates that the use of selective and indiscriminate violence is related to the control of territory (Kalvas, 2012). The model is divided into two parts. The first part is concerned with alliances and transactions between supralocal and local actors, whereby local actors (e.g. civilians) are considered valuable resources and control over them in conflicts (especially civil wars [1]) is vital (Vargas, 2009, 111). This part of the model argues that violent actors in a conflict desire the collaboration of civilians (especially in disputed territory) and therefore 
are often driven to secure their cooperation through violent means. Additionally the incumbent actor is often forced to compete with insurgents for control over the population (Kocher, 2008, 5) and therefore may decide to destroy the population if it feels it will not be able to use it as a strategic resource. The second part of this model considers the evolution and spatial distribution of indiscriminate and selective violence (Kocher, 2008, 5). Kalyvas argues that the use of indiscriminate violence [2] is inversely related to the level of territorial control. Indiscriminate violence is employed in areas where an actor experiences disputed territorial control, whereas selective violence is employed in areas where an actor enjoys levels of complete control (Kalvas, 2012, 661). The model also argues that the use of indiscriminate violence is most prevalent during periods of territorial loss. In The Logic of violence in Civil War (2006) Kalyvas divides the variable of 'territorial control' into zones, ranging from secure incumbent control to secure insurgent control (Kalyvas, 2006, 16). Building on this model this study utilises the below 5 zones of control:

Zone 1: secure (incumbents)

Zone 2: insecure (incumbents)

Zone 3: contested

Zone 4: insecure (insurgents)

Zone 5: secure (insurgents).

According to the model, the use of indiscriminate violence will be most common in zones 2 -4, while zones 1 and 5 will experience little indiscriminate violence but higher levels of selective violence (Kalyvas, 2006).

This study tests the 2nd part of this model. Through the use of data gathered from the 'Syrian Martyr Database', this study considers the use of indiscriminate violence by Syrian state forces over a period of 45 weeks (April 2012-January 2013) in the city of Aleppo. This author contends that high levels of noncombatant casualties is indicative of the use of indiscriminate violence. Therefore the data analysed in this study consists of civilian and child deaths as a function of territorial control and territorial loss. The 45 week period is divided into three 15 week periods. Period 1 constitutes a time of secure incumbent (state) control (zone 1); period 2 constitutes a time of insecure incumbent control (zone 2); and, period 3 constitutes a time of contested territorial control between incumbent and insurgent forces (zone 3).

This study will firstly examine the existing literature on this subject and consider the validity and reliability of the control-collaboration model in other contexts. Secondly, details of the methodology of this study will be provided before the data is analysed and discussed. The results of the data analysis provide evidence to support Kalyvas' argument that lower levels of territorial control lead to higher levels of indiscriminate violence and that the initial loss of territory leads to even greater levels of indiscriminate violence. However, this study is limited to testing just two of the components of this model and thus merely justifies the need for greater analysis of the Syrian conflict. Access to more detailed and comprehensive data would allow for the full testing of this model, including levels of selective violence, different forms of indiscriminate violence, and the motivations behind their use.

\section{Literature Review}

In 1935 the publication of The Incidence of the Terror during the French Revolution (1935) by Greer marked the first statistical-based study to use territorial control as a variable in the study of violence. Studying data on executions by region during the French Reign of Terror, Greer noted that, "It is at once apparent that certain 


\section{Journal of Terrorism Research}

regions bore the brunt of the Terror while others escaped almost unscathed." (qtd Louie, 1964, 380). Since Greer's work, the study of intra-state conflict and violence has continued this trend of macro econometric study. However the continuous improvement in data availability has allowed for new studies on the microdynamics of intra-state conflict to emerge, which in taking a sub-national focus, allow for the possibility of testing micro-foundations, causal mechanisms and improving the links between concepts and data (Kalyvas et al, 2008, 397). Since the control-collaboration model was published in 2006, it has been applied to different national, regional and local contexts. It is important to consider the findings of other scholars and theorists in order to gage the strengths and weaknesses of the control-collaboration model before proceeding with this current study.

Kocher and Kalyvas provide one of the earliest tests of the control-collaboration model in their 2008 study on the determinants of violence against civilians during the Vietnam War (Kocher; Kalyvas, 2009). Taking the hamlet as the territorial unit of analysis the authors conclude that indiscriminate violence affecting civilians, was a function of the level of territorial control of both sides: South Vietnamese and US forces performed acts of indiscriminate violence in territory that had less control over and exercised selective violence in areas that they dominated (Kocher; Kalyvas, 2009, 335). In a very different context Gonzalo Vargas studied the use of coercion and violence against civilians during an urban irregular war in the Colombian city of Barrancabermeja from 1998 onwards (Vargas, 2009). Vargas found that guerrillas fighting state counter-insurgency forces used high levels of indiscriminate violence in areas that were contested or they had little control over, yet, in contradiction to Kalyvas' model, employed very little selective violence in areas that they controlled (Vargas, 2009, 126). In a more comprehensive study Bhavnani et al (2012) and considered outbreaks of violence between Israelis and Palestinians between 1987-2005 and noted that indiscriminate violence was used in areas of disputed or non-existent territorial control in order to overcome identification problems due to lack of precise information on who constituted the enemy, as well as a means of deterring collaboration through the form of collective punishment (Bhavnani et al, 2012; Wood, 2010). The problematic effect that territorial control has on information is echoed by Schutte in his analysis of 11 different cases of insurgency (Schutte, 2013). In his 'distance-decay' model Schutte notes that an actor's inability to distinguish between neutral or allied civilians and enemy collaborators increases as the distance from their 'power centre' increases (Schutte, 2013, 1). Along similar lines to this present study, Ziemke conducted an analysis of approximately 10,000 geo-referenced observations of massacres and battle events during the Angolan war, considering not just different stages of territorial control but also the process of territorial loss (Ziemke, 2008). In agreement with the conclusions made in this study, Ziemke concluded that the level of indiscriminate violence against civilians is a function both of territorial control and of territorial loss, with post-battle territorial losses leading to the greatest levels of civilian abuse and massacres (Ziemke, 2008). Other studies such as Fagerlund (2011), Hultman (2007, 2008), Metelits, (2010), Straus, (2012), Wood (2010), Zhukov (2013) also use qualitative and quantitative methods to vindicate Kalyvas' framework and well as underline the importance considering violence as representing a strategic continuation of the bargaining process.

Although this study does not extend to examining the motivations and effectiveness of the use of indiscriminate violence it does provide the first step toward a more detailed study agenda. The role and effects of territorial control have been examined and statistically analysed in many different contexts and the model has been proved largely water-tight. However the Syrian crisis has not yet been used as a subject of analysis. This study therefore represents a continuation of the rapidly advancing field of the micro-dynamics of intra-state conflict. As well as being a current event, the Syria crisis represents a very interesting and 


\section{Journal of Terrorism Research}

challenging subject of analysis. Syria's history of ethnic and sectarian divisions and its background of extreme instability have helped create the conditions for the present-day conflict (Smith, 2012, 1). Although this study only accounts for two actors (state and rebel forces), Syria is made up of many groups, including the majority Sunni Muslims (74\%), the ruling Alawis (12\%), Christians (10\%) and Druze (4\%) (Hopwood, 1988, 9), as well as foreign fighter groups such as Hezbollah. The Syria crisis therefore represents a complicated, yet valuable untapped resource for micro quantitative study.

Before proceeding to detail the methodology of this study, the control-collaboration model and the above literature allow for several hypotheses to be drawn to test the relationship between territorial control and indiscriminate violence:

H1: Period 1 (zone 1) will experience the lowest level of indiscriminate violence.

H2: Period 2 (zone 2) will experience the highest level of indiscriminate violence as it represents both a level of insecure incumbent control and occurs at a time of territorial loss.

H3: Period 3 (zone 3) will experience a high level of indiscriminate violence. However no further territory has been lost since period 2. Therefore period 3 will experience lesser levels of indiscriminate violence than period 2 .

\section{Methodology}

This study takes its data sample from the Syrian Revolution Martyr Database (syrianshuhada.com). This online database contains a comprehensive collection of data on the Syrian Crisis death toll. The database compiles data from five principle sources: The Violations Documentation Centre in Syria (VDC), the Syrian Centre for Human Rights (SCHR), the Syrian Network for Human Rights (SNHR), the Local Coordination Committees of Syria (LCC) and The Syrian Revolution Database. The database also uses information obtained from social media and news network sites. To date it has listed the deaths of 89,376 people, including 8,733 in Aleppo, over a period of 998 days (syrianshuhada.com).

Data on the daily deaths of children and civilians over the course of a 45 week period (from 1.4.2012 to 12.1.2013) in Aleppo was gathered. The city[3] of Aleppo was chosen as a unit of analysis since it has been a centre-point of clashes between rebel and state forces. Events have also been widely reported on and data is therefore more readily available. The daily death tolls were added up each 7 days to allow for a weekly total. Data and calculations (including weekly totals, standard deviations and period means) were used to descriptively analyse the fluctuations by week and between periods, as well as conduct inferential statistical and post-hoc tests to quantify the difference in civilian and child deaths between periods (ANOVA testing at $5 \%$ significance was carried out to analyse variance between groups and a post-hoc Tukey-HSD test, also at $5 \%$ significance, was carried out to analyse the difference in means between periods).

Data on the nature of deaths was insufficient to allow for distinction to be made between different methods of violence (e.g. aerial bombardment or missile strikes). This study therefore rests on the assumption that civilian deaths and child deaths are, in general terms, an indicator of indiscriminate forms of violence committed by the incumbent actor. In making this assumption this author acknowledges the potential risk of omitted variable bias. Additionally given the nature of the data source (an anti-government organisation), the risk of bias and the conflation of civilian and rebel fighter must also be acknowledged. Therefore until data has been further triangulated and sources verified by impartial bodies, the results of this study must be treated at best as a general indictor, rather than a statement of undisputed fact. 


\section{Journal of Terrorism Research}

As Kalyvas and Kocher noted with regards to this topic of research, "...the main obstacles to establishing external validity are the lack of data on control and the absence of disaggregated data on selective and indiscriminate violence." (qtd Bhavnani et al, 2011, 62). Due to this, selective violence will not be considered in this particular test of the control-collaboration model since, with the data available, it is harder to determine. On the other hand, territorial control (as the causal variable) is possible to measure in terms of zoning (although quantifying it precisely is beyond the scope of this study). The time period chosen in this study is a reflection of an evolution in territorial control over Aleppo[4]:

Period 1: Small-scale uprisings and protests occurred but the state retained full control over the city.

Period 2: Rebel forces attacked the city and state forces immediately lost control of rural areas and sections of Aleppo city but retained control over strategically important areas.

Period 3: Rebel forces made small gains, followed by periods of retreat. Territorial control over the city remained contested and at a stalemate (as shown below).

Figure 1: Aleppo territorial control in September 2013

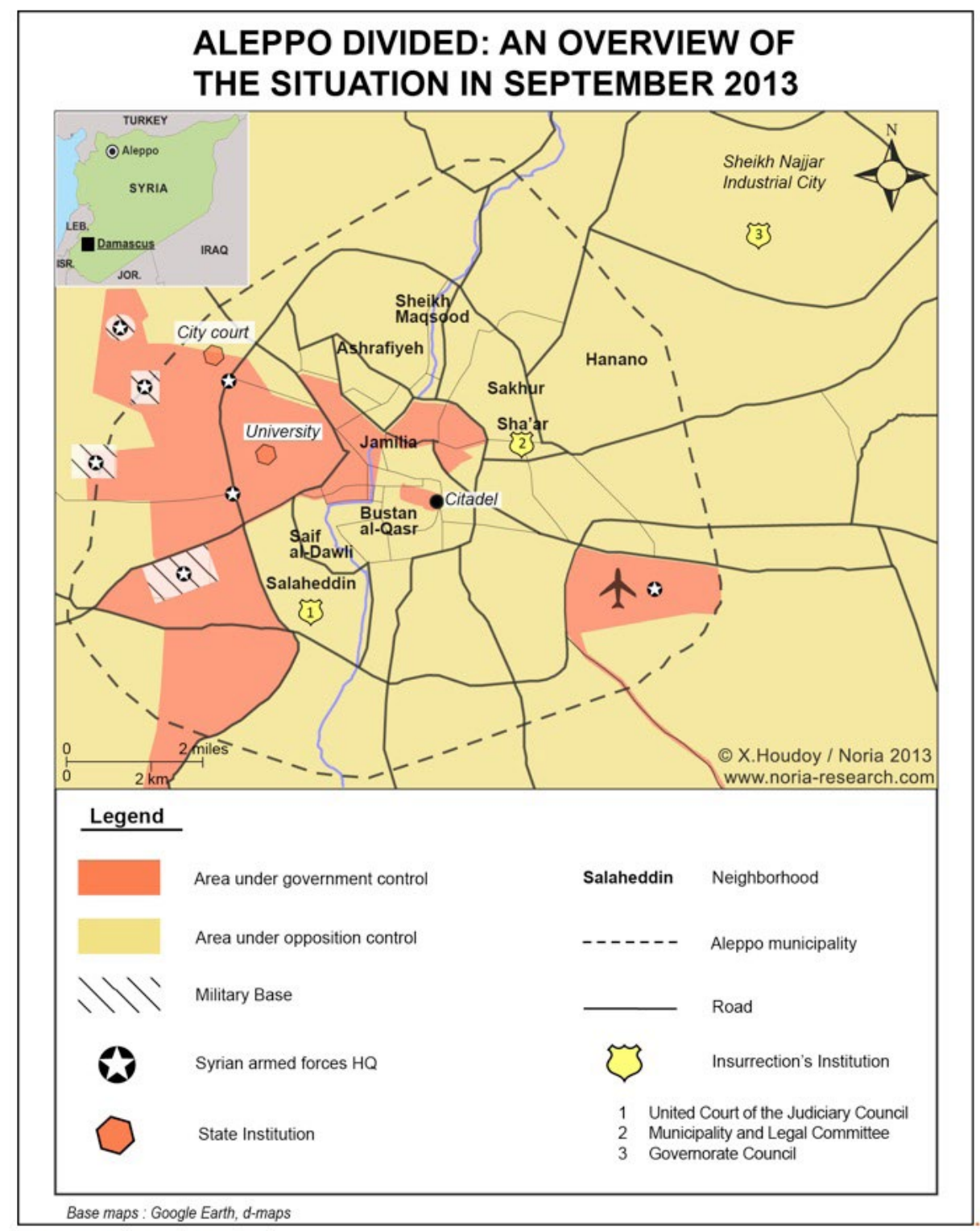

(noria-research.com) 


\section{Analysis}

\section{i. Aleppo in Numbers}

In line with Hypothesis 1, period 1 (zone 1) sees the lowest number of both child and civilian causalities (162 and 50 respectively, as shown in graph 1 below, where blue bars indicate levels or civilian death and red bars indicate child deaths). The mean values of 10.8 and 3.33 (civilian and child deaths per week) suggest low levels of indiscriminate violence by incumbent forces. Relatively low standard deviation values (5.65 and 2.85) show that weekly dispersion from the period average is not significant. It is thus more likely that non-combatant deaths occurred during this period as a result of street fighting, riots and minor clashes, rather than by events such as aerial bombardment or missile strikes (media sources that reported the use of indiscriminate violence during this period could not be located).

In contrast, period 2 (zone 2) sees a sharp increase in civilian and child deaths (totalling 2,399 civilian and 417 child deaths over 15 weeks). Weekly mean values of 159.93 and 27.8 mark a stark contrast from period 1 and provide evidence for Hypothesis 2: Period 2 (zone 2), occurring at a time of territorial loss, will experience the highest level of indiscriminate violence. The high standard deviation values (60.85 and 14.12) show that weekly dispersion from the period average is significant. This adheres to the incumbent's violent reaction during times of immediate loss. For example on the 24th of July a Free Syrian Army offensive to capture parts of the city centre pushed incumbent forces back. The Syrian Army then retaliated with missile strikes across the city (Weaver; Whitaker, 2012). This perhaps explains why the civilian death toll jumped to 190, compared to 40 the week before. Graph 2 (below) shows the variations in weekly sums of civilian and child deaths over the 45 week period[5].

In line with Hypothesis 3, period 3 (zone 3) continues to see high civilian and child death tolls, yet at lower levels than experienced during period 2. High means of 107.53 and 19.4 suggest that levels of indiscriminate violence remain high, yet as territorial control remains contested and there has not been any periods of loss during this time, there has been a tapering in the use of indiscriminate violence. High standard deviation values (47.23 and 9.15) are again however suggestive of sporadic uses of indiscriminate violence. For example an aerial bombing and tank shelling campaign occurred at the end of January, meanwhile the massacre of civilians was reported ('Syria', bbc.co.uk). During this particular week, civilian and child casualties jump to 220 and 44 from 73 and 11 the week before. 
The Centre for the Study of Terrorism and Political Violence

\section{Journal of Terrorism Research}

Graph 1: Civilian and Child Deaths by Period

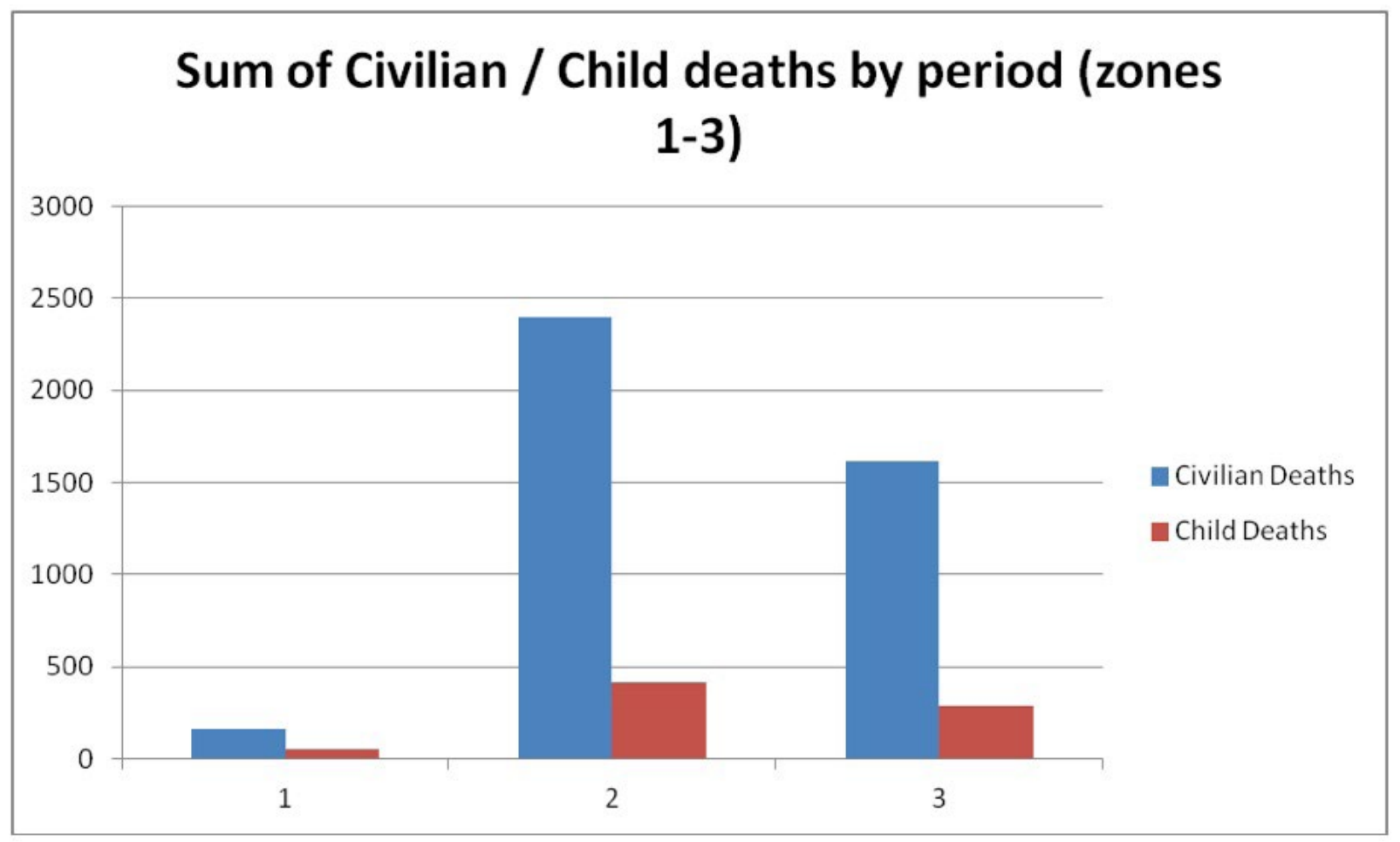

Graph 2: Civilian and Child deaths by Week

Civilian and Child deaths in Aleppo over 45 weeks

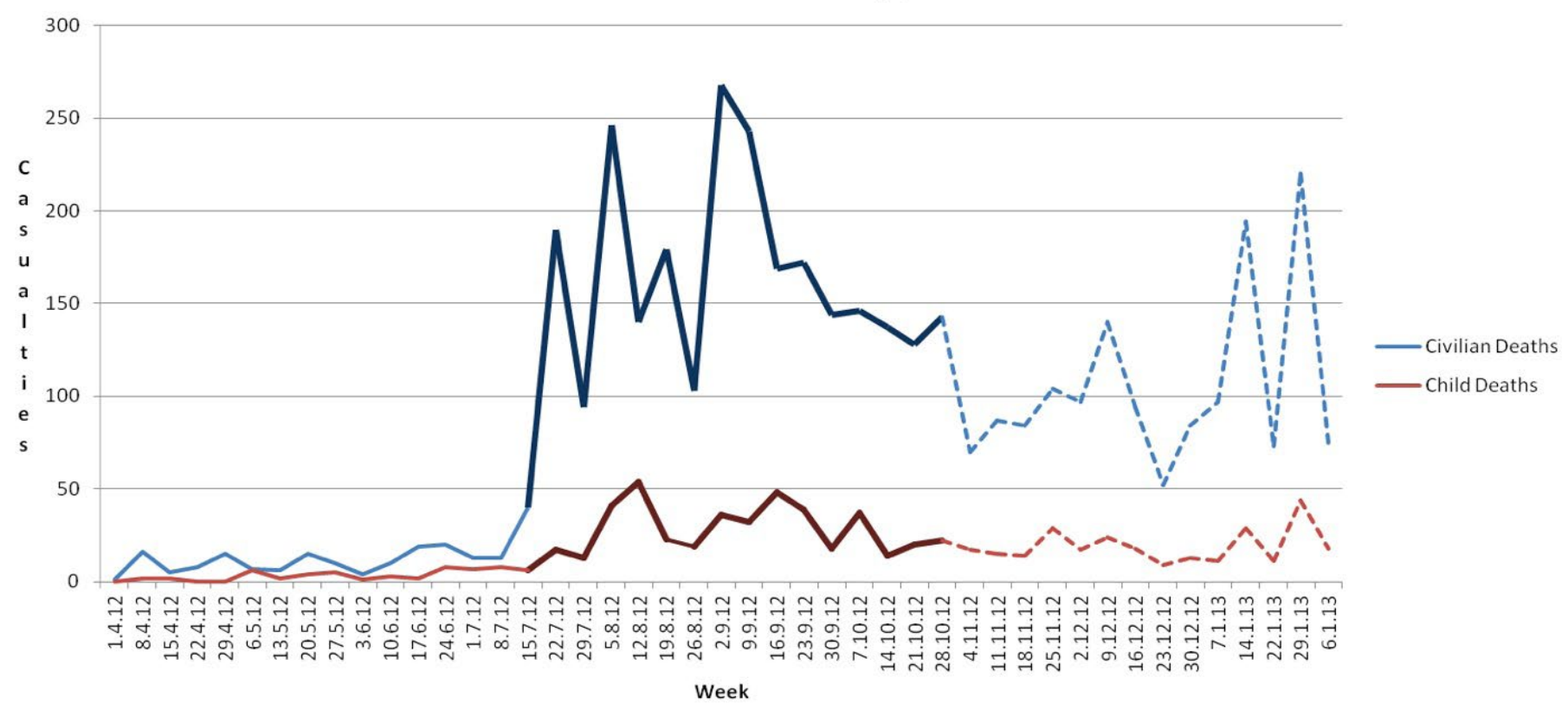

\section{ii. Statistical Analysis of Aleppo}

Although the difference in levels of civilian and child casualties between the three 15 week periods are clearly 


\section{Journal of Terrorism Research}

observable, it is also important to quantify as well as describe this difference in order to determine whether it is statistically significant. To achieve this aim, this study first conducted a single factor, or one-way ANOVA (analysis of variance) test at 5\% significance. ANOVA testing is used to test the null hypothesis that the means of several samples are all equal, against the alternative hypothesis that the means of several samples are different. The full results of the ANOVA testing for civilian and child deaths data samples are listed in the appendix, under the headings: Table 4 and Table 5.

The important values to consider in this test are the $\mathrm{F}$ and $\mathrm{F}$ critical values. An $\mathrm{F}$ value larger than an $\mathrm{F}$ critical value means that the difference in means between periods is statistically significant. Table 4 shows an F value, or ratio, (43.19) larger than the F critical value of 3.22. Table 5 also shows an F value (23.71) larger than the F critical value of 3.22. Thus in both cases there is significant difference between means and the null hypothesis is rejected in favour of the alternative hypothesis. In other words, according to the data presented, there is evidence to suggest that change in death rates between periods is statistically significant.

In order to examine where these differences lie and to determine whether there is statistically significant difference from one period to another (e.g. between 1-2, 2-3 and 1-3) a post-hoc Tukey-HSD (honest significant difference) test was conducted (also at a 5\% significance level) using the information provided in the ANOVA tests. The HSD value is used to compare with the ratio between means. An HSD value greater than the difference between two means allows for the rejection of the null hypothesis in favour of the alternative hypothesis.

Using the values in the ANOVA results table a Tukey-HSD test, using JMP software for calculation gave the results for civilian casualties measuring an $\operatorname{HSD}(.05)=39.58$ and for child casualties an $\operatorname{HSD}(.05)=8.78$. Furthermore, the differences in mean values for civilian deaths between periods 1 and 2 is 148.2 (159.93 10.8), the difference between periods 2 and 3 is 52.4 (159.93 - 107.53) and between periods 1 and 3 is equal to 96.73 (107.53 - 10.8). For civilian casualties each of the mean comparisons show values greater than the HSD value of 39.58. Therefore they are all statistically significantly different, with the greatest difference being between periods 1 and 2 .

The differences in mean values for child deaths between periods 1 and 2 is 24.47 (27.8 - 3.33), the difference between periods 2 and 3 is $8.4(27.8-19.4)$ and between periods 1 and 3 is equal to $16.07(19.4-3.33)$. Mean comparisons between periods 1 and 2, and between periods 1 and 3 show values greater than the HSD value of 8.78 and therefore show statistically significant difference. Difference between periods 2 and 3 however is not large enough to be considered statistically significant. Therefore in this particular case the hypothesis that there is not a statistically significant different between child deaths over these two periods (null hypothesis), may not be rejected.

Lastly a correlation coefficient was calculated between civilian and child deaths over the entire 45 week period. The correlation between the two samples gave a value of $r=0.85$. This value represents a very strong positive linear relationship between civilian and child deaths. This final test was carried out to help nullify the potential error in miscategorising rebel fighters (or insurgents) as civilians. There is far less ambiguity between children and insurgents than there is between civilians and insurgents and therefore a low correlation value would have forced this study to reconsider the accuracy of using civilian casualties as an indicator of indiscriminate violence. 


\section{Journal of Terrorism Research}

\section{Discussion}

Referring back to the initial research question, results from this study have, for the most part, vindicated the indiscriminate violence assumption of the control-collaboration model. Descriptive statistics, ANOVA testing and post-hoc Tukey-HSD testing has shown that there is statistically significant difference between periods 1-2, 2-3, and 1-3, of civilian casualties, and hence an inverse relationship between levels of territorial control and territorial loss on one hand, and the use of indiscriminate violence on the other, throughout the course of April 2012 to January 2013 in Aleppo. Hypotheses 1, 2 and 3, generated from the assumptions made in the model, were thus confirmed.

Descriptive and inferential statistical analysis has provided results[6] which echo the conclusions drawn by many of the authors discussed earlier. As in Ziemke's study, the highest levels of indiscriminate violence occurred during the initial process of losing territory (period 2). These conclusions are also supported by the observations of media, intelligence, NGO and human rights groups. The American Association for the Advancement of Science (AAAS), for example, conducted a satellite observation programme of Aleppo throughout the conflict and has stated that, "The spatial distribution of destruction in Aleppo is severely lopsided with respect to political control. Of the 713 instances that were observed during the study period, only six occurred in areas reported to be occupied by regime forces." ('Staff Report', aaas.org). The same reported also concluded that the "...striking dichotomy in damage, in conjunction with direct observations of military activity, is consistent with reports that government forces have been using aircraft, missiles, and long-range artillery to bombard rebel-held areas." ('Staff Report', aaas.org). Satellite images (such as figure 2 below) further evidence the use of indiscriminate violence in non-incumbent controlled areas and help explain the sudden spikes in death figures during given weeks, as can be clearly observed in graph 2 (such as during the week of 2.9.2012). Again however it is important to note the risk of omitted variable bias. The Syrian conflict has involved a large number of domestic and international actors, who all affect regime action in different ways. For example, it is possible that use of indiscriminate violence declined from period 2-3 due to international pressure, the threat of foreign intervention and/or through the influence of strategic allies, such as Russia and Iran. Further in-depth study is needed in order to discount the potential effects of confounding variables.

Figure 2: Effects of Aerial Bombardment
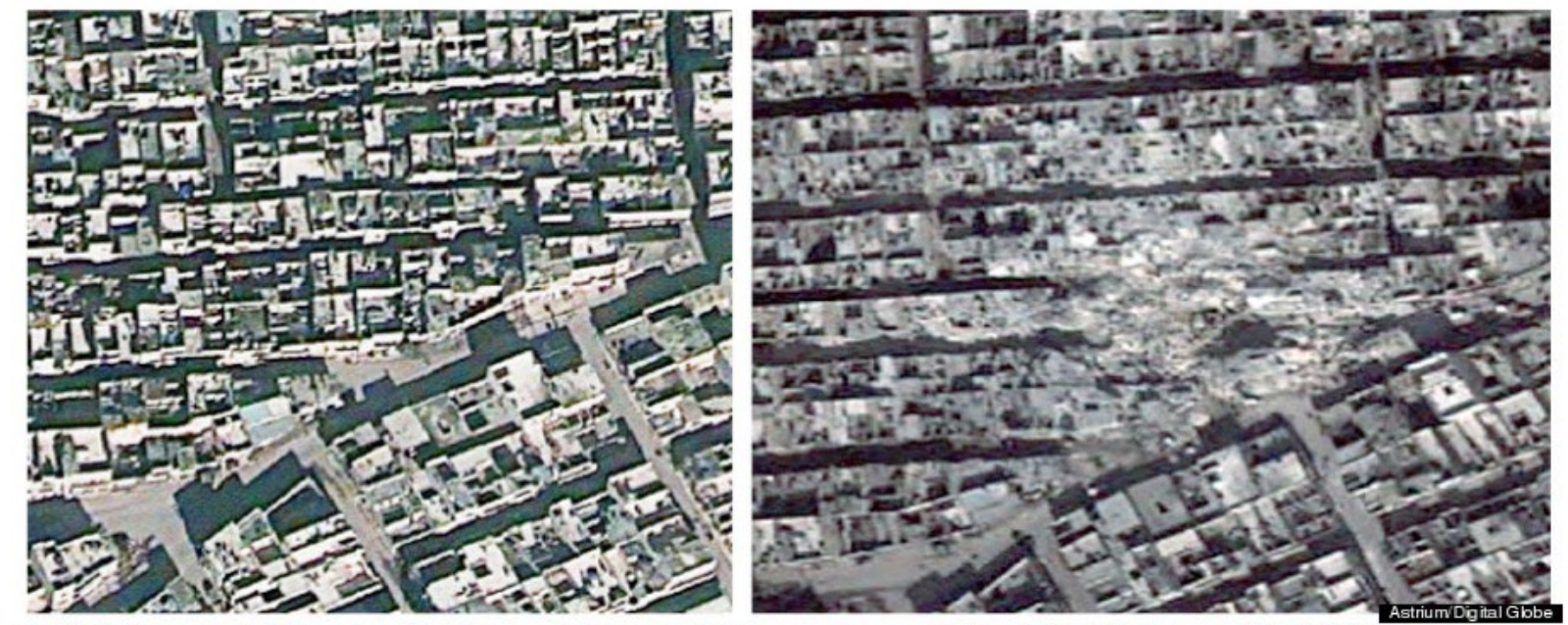

Ard al-Hamra neighbourhood, Aleppo, before and after a regime missile strike (February 22, 2013) (Davis,

2013) 


\section{Journal of Terrorism Research}

Despite the conclusions reached, this study remains limited to providing evidence for just two assumptions of the control-collaboration model. The first part of the model, which focuses on the motivations behind the use of violence, as well as the remainder of the second part of the model, including the use of violence by insurgent forces and the use of selective violence, remain outside the scope of this study. Ultimately as Thucydides noted, civil wars encourage the privatisation of violence and involve a vast array of motivations and actors in what is a 'war of all against all'. (Kalyvas, 2003, 475). It is not clear in this case what motivated incumbent forces to use indiscriminate violence. This study has thus marked a starting point and has emphasised the requirement for greater study into the micro-dynamics of the Syrian crisis. Eck and Hultman's findings on regime type as a determiner of the use of indiscriminate violence, Schutte's 'distancedecay' model, Metelits' argument on territorial 'bargaining' and Bhavnani's thesis on the nexus between information and use of indiscriminate violence could all potentially prove insightful in examining the motivations behind the Syrian regime's use of violence.

Lastly it is important to note that the results of this study also serve to question the labelling of Syrian state forces as a terrorist actor (in the case of Aleppo). Mitchell describes state terrorism as, “...deliberate coercion and violence directed at some victim, with the intention of inducing extreme fear in the target observers who identify with that victim in a way that they perceive themselves as potential future victims." (Schmid, 2011, 127). This definition does indeed adhere to the effects of indiscriminate violence performed by incumbent forces, and possibly the motivation behind its use. However, the use of indiscriminate violence in areas of insecure or low territorial control falls against the arguments of state terror literature which note that state terror is a direct function of high government control (Kalyvas, 2006,17). This study therefore casts doubt on some of the theoretical assumptions made by state-terrorism scholars. Wider study of the Syrian conflict is necessary however before such claims can be judged externally valid to the entire zone of conflict.

\section{Conclusion}

This study has examined an area of civil war and domestic and international crisis, which to date has been largely unexplored by micro-dynamic theorists of intra-state conflict. While acknowledging the limitations and potential faults of this study, the data gathered and the subsequent analysis has provided strong evidence to support two key assumptions of the control-collaboration model. Firstly data from the 45 week period of the Battle of Aleppo has shown that the level of territorial control is inversely related to the rate of death of civilians and children, and thus also the use of indiscriminate violence by incumbent forces. Secondly, the loss of territory is accompanied by an increase in the death rate of civilians and children, again representative of a higher rate of indiscriminate violence. To return to the initial research question, territorial control and the loss of territory do indeed determine the use of indiscriminate violence by the incumbent actor in Aleppo, Syria, over the time period analysed.

Although the use of indiscriminate violence is seen by most as repugnant, its very existence is testament to the belief that it can be an effective tool of counterinsurgency (Kocher, 2008, 2). The results of this study suggest, as concluded by many of the authors discussed, civilians, rather than soldiers, are the tactical targets in this conflict (Rueda, 2013). It is essential now to advance this research agenda and to examine why exactly civilians become the victims of territorial conflict. Are violent actors in the Syria conflict motivated by a will to punish, a will to achieve bargaining power, or, simply an inability to employ selective violence against their enemies? This study has made important discoveries, yet in doing so has also produced a series of questions to be answered. The Syrian crisis is one of the greatest security, geopolitical and humanitarian issues facing 


\section{Journal of Terrorism Research}

the international system today, and greater understanding of the micro-dynamics of the conflict may prove useful in crisis management, diplomacy, humanitarian relief and conflict resolution.

About the author: Evan Tyner is a recent graduate from the University of St Andrews where he obtained an MA in International Relations and an MLitt in Terrorism Studies. He is currently working in Brussels at the European Institute of Peace (EIP), where he retains a focus on violent extremism and political violence. He continues to conduct research on terrorism and the activities of armed groups, with particular focus on the MENA region.

\section{Notes}

[1] Defined by Kalyvas as "...armed combat within the boundaries of a recognized sovereign entity between parties subject to a common authority at the outset of the hostilities." (qtd Bhavnani et al , 2011, 62).

[2] Although he does not provide a definitive definition of indiscriminate violence, Kalyvas classifies the intentional use of 'cheap' military technologies such as artillery, bombs, missile strikes and aerial bombardment as indiscriminate methods (Kocher, 2008, 6).

[3] Although using a city as a unit analysis, rather than a more macro unit, may reduce external validity to the wider conflict, it also increases the internal validity of the study and helps reduce the risk of observational equivalence, endogeneity and over-aggregation.

[4] The dates chosen for each period are a reflection of the troop movements and control held by either side according to news sources and International Organizations that reported on the Battle of Aleppo (UNHCR. org; crisisgroup.org; bbc.co.uk). They have been chosen at the author's discretion based on the trends reported by the above organisations.

[5] The fine blue and red lines represent period 1; the bold lines represent period 2; and the dotted lines represent period 3.

[6] With the only exception being in the mean ratio of child deaths between periods 2 and 3.

\section{References}

American Association for the Advancement of Science (AAAS), 'AAAS Report Shows Steady Escalation of Destruction in Aleppo', Staff Report (aaas.org), P: 2.8.2013, A: 12.12.2013.

Arendt, H., (1969). On violence. New York: Harcourt Brace and Company.

BBC online, 'Syria', (bbc.co.uk), accessed 10 December 2013.

Bhavnani, R., Miodownik, D., Choi, H., (2012), 'Three Two Tango: Territorial Control and Selective Violence in Israel, the West Bank, and Gaza', Journal of Conflict Resolution, 55: 1, pp. 133-158.

Bhavnani, R., Miodownik, D., Choi, H., (2011) 'Violence and Control in Civil Conflict: Israel, the West Bank, and Gaza', Comparative Politics, 44: 1, pp. 61-80.

Eck, K., Hultman, L. (2007) 'One-Sided Violence Against Civilians in War: Insights from New Fatality Data', Journal of Peace Research, 44: 2, pp. 233-246;

Fagerlund, E. (2011), 'The Tigers' Roar: Insurgent Violence Against Civilians in Sri Lanka', Psychology \& Society, 4 : 1, pp. $96-11$ 


\section{Journal of Terrorism Research}

Hopwood, D., (1988) Syria 1945-1986, Unwin Hyman: London.

Hultman, L. (2008) 'Targeting the Unarmed: Strategic Rebel Violence in Civil War', Unpublished manuscript.

International Crisis Group, 'Syria', (crisisgroup.org), accessed 10 December 2013.

Kalyvas, S. (2012) 'Micro-Level Studies of Violence in Civil War: Refining and Extending the Control-

Collaboration Model', Terrorism and Political Violence, 24:4, pp. 658-668

Kalyvas, S., Kocher, A. (2009) 'The Dynamics of Violence in Vietnam: An Analysis of the Hamlet Evaluation System (HES)', Journal of Peace Research, 46: 3, pp. 335-355.

Kalyvas, S., Shapiro, I., Masoud, T. (2008) Order, Conflict, and Violence. Cambridge, UK: Cambridge UP.

Kalyvas, S. (2006) The Logic of Violence in Civil War. Cambridge: Cambridge UP.

Kalyvas, S. (2003) 'The Ontology of "Political Violence": Action and Identity in Civil Wars', Perspectives on

Politics, 1:3, pp. 475-494

Kocher, (2008), 'Aerial Bombardment, Indiscriminate Violence, and Territorial Control in Unconventional

Wars: Evidence from Vietnam.', Paper prepared for presentation at the Annual Meeting of the American

Political Science Association Boston, MA August 28 - 31, 2008. Unpublished manuscript.

Louie, R. (1964) 'The Incidence of the Terror: A Critique of a Statistical Interpretation', French Historical Studies, 3: 3, pp. 379-389.

Metelits, C. (2010) Inside Insurgency: Violence, Civilians, and Revolutionary Group Behavior, New York: New York Press.

Noria Research - Network of Researchers in International Affairs, (noria-research.com), Map uploads 2013, P: September 2013, A: 9.12.2013.

Rueda, M. (2013), ' Popular Support, Denunciations and Territorial Control in Civil War'. Unpublished manuscript.

Schmid, A. (2011) The Routledge Handbook of Terrorism Research. New York: Routledge.

Schutte, S. (2013) 'Geographical determinants of indiscriminate violence in civil wars., ETH Zurich, Paper prepared to be presented at the meeting of the European Network of Con_ict Research, Amsterdam,

Netherlands, April 24-26, 2013.

Smith, B., (2012), 'Syria: No End in Sight?', Research Paper 12/48, House of Commons library.

Solomon, R., Syria Death Toll Hits Nearly 126,000, Reuters, (reuters.com), P: 2.12.2013, A: 2.12.2013.

Straus, S. (2012) “'Destroy Them to Save Us”: Theories of Genocide and the Logics of Political Violence', Terrorism and Political Violence, 24:4, pp. 544-560.

Syrian Revolution Martyr Database (url: syrianshuhada.com), A: 8.12.2013.

United Nations High Commission for Refugees (UNHCR), 'Syria Profile', ( www.unhcr.org), accessed 10 December 2013.

United Nations Security Council (UNSC) 'Alarmed by Continuing Syria Crisis, Security Council Affirms Its Support for Special Envoy's Approach in Moving Political Solution Forward', SC/12008, 7504th Meeting. Accessed 28.01.16.

Vargas, G. (200) 'Urban Irregular Warfare and Violence Against Civilians: Evidence From a Colombian City', Terrorism and Political Violence, 21: 1, pp. 110-132. 


\section{Journal of Terrorism Research}

Weaver, M., Whitaker, B., Middle East Live-Syria crisis: rebels 'execute shabiha' in Aleppo-Wednesday 1 August 2012, The Guardian, (theguardian.com), P: 1.8.2012, A. 11.12.2013.

Wood, R. (2010), 'Competing for Control: Conflict Power Dynamics, Civilian Loyalties and Violence in Civil War', University of North Carolina. Unpublished manuscript.

Zhukov, Y. (2013), 'A Theory of Indiscriminate Violence in Civil War', Unpublished manuscript.

Ziemke, J. (2008) 'From Battles to Massacres' Prepared for the 3rd Annual Harvard-Yale-MIT Graduate Student Conference on Order, Conflict and Violence. Unpublished manuscript.

\section{Appendix}

\section{Periods 1-3:}

Table 1

\begin{tabular}{|l|r|r|}
\hline Week & Civilian Casualties & Child Casualties \\
\hline 1.4 .12 & 1 & 0 \\
\hline 8.4 .12 & 16 & 2 \\
\hline 15.4 .12 & 5 & 2 \\
\hline 22.4 .12 & 8 & 0 \\
\hline 29.4 .12 & 15 & 0 \\
\hline 6.5 .12 & 7 & 6 \\
\hline 13.5 .12 & 6 & 2 \\
\hline 20.5 .12 & 15 & 4 \\
\hline 27.5 .12 & 10 & 5 \\
\hline 3.6 .12 & 4 & 1 \\
\hline 10.6 .12 & 10 & 3 \\
\hline 17.6 .12 & 19 & 2 \\
\hline 24.6 .12 & 20 & 8 \\
\hline 1.7 .12 & 13 & 7 \\
\hline 8.7 .12 & 13 & 8 \\
\hline & & \\
\hline Sum & 162 & 50 \\
\hline Mean & 10.8 & 3.33 \\
\hline S.D. & 5.65 & 2.85 \\
\hline & & \\
\hline & & \\
\hline
\end{tabular}


The Centre for the Study of Terrorism and Political Violence

\section{Journal of Terrorism Research}

\begin{tabular}{|l|r|r|}
\hline Week & \multicolumn{1}{|l|}{ Civilian Casualties } & Child Casualties \\
\hline 15.7 .12 & 40 & 6 \\
\hline 22.7 .12 & 190 & 17 \\
\hline 29.7 .12 & 94 & 13 \\
\hline 5.8 .12 & 246 & 41 \\
\hline 12.8 .12 & 140 & 54 \\
\hline 19.8 .12 & 179 & 23 \\
\hline 26.8 .12 & 103 & 19 \\
\hline 2.9 .12 & 268 & 36 \\
\hline 9.9 .12 & 243 & 32 \\
\hline 16.9 .12 & 169 & 48 \\
\hline 23.9 .12 & 172 & 39 \\
\hline 30.9 .12 & 144 & 18 \\
\hline 7.10 .12 & 146 & 37 \\
\hline 14.10 .12 & 137 & 14 \\
\hline 21.10 .12 & 128 & 20 \\
\hline & & \\
\hline Sum & 2399 & 417 \\
\hline Mean & 159.93 & 27.8 \\
\hline S.D. & 60.85 & 14.12 \\
\hline & & \\
\hline
\end{tabular}




\section{Journal of Terrorism Research}

Table 3

\begin{tabular}{|l|r|r|}
\hline Week & Civilian Casualties & Child Casualties \\
\hline 28.10 .12 & 143 & 22 \\
\hline 4.11 .12 & 70 & 17 \\
\hline 11.11 .12 & 87 & 15 \\
\hline 18.11 .12 & 84 & 14 \\
\hline 25.11 .12 & 104 & 29 \\
\hline 2.12 .12 & 97 & 17 \\
\hline 9.12 .12 & 140 & 24 \\
\hline 16.12 .12 & 94 & 18 \\
\hline 23.12 .12 & 52 & 9 \\
\hline 30.12 .12 & 84 & 13 \\
\hline 7.1 .13 & 97 & 11 \\
\hline 14.1 .13 & 194 & 29 \\
\hline 22.1 .13 & 73 & 11 \\
\hline 29.1 .13 & 220 & 44 \\
\hline 6.1 .13 & 74 & 18 \\
\hline & & \\
\hline Sum & 1613 & 291 \\
\hline Mean & 107.53 & 19.4 \\
\hline S.D. & 47.23 & 9.15 \\
\hline & & \\
\hline
\end{tabular}

Table 4 - Civilian Deaths

\begin{tabular}{|l|l|l|l|l|l|l|}
\hline ANOVA & & & & & & \\
\hline Source of Variation & SS & $d f$ & MS & F & P-value & F crit \\
\hline Between Groups & 171719.2 & 2 & 85859.62 & 43.1946 & $6.44 \mathrm{E}-11$ & 3.219942 \\
\hline Within Groups & 83485.07 & 42 & 1987.74 & & & \\
\hline & & & & & & \\
\hline Total & 255204.3 & 44 & & & & \\
\hline
\end{tabular}

Table 5 - Child Deaths

\begin{tabular}{|l|l|l|l|l|l|l|}
\hline ANOVA & & & & & & \\
\hline Source of Variation & SS & $d f$ & MS & F & P-value & F crit \\
\hline Between Groups & 4636.578 & 2 & 2318.289 & 23.70592 & $1.29 \mathrm{E}-07$ & 3.219942 \\
\hline Within Groups & 4107.333 & 42 & 97.79365 & & & \\
\hline & & & & & & \\
\hline Total & 8743.911 & 44 & & & & \\
\hline
\end{tabular}

